\title{
DESAFIOS COMUNICACIONAIS NO MERCOSUL ${ }^{1}$
}

\author{
Globalização e multiculturalismo são aspectos que colaboram \\ para ampliar as relações culturais entre os países do Cone-Sul
}

A América Latina constitui um mosaico cultural marcado pela diversidade. Antes do advento dos primeiros navegadores ibéricos - os hispânicos guiados por Colombo e os lusitanos liderados por Cabral -, as populações indígenas aqui existentes já se caracterizavam pela pluralidade dos modos de viver. Os colonizadores acrescentaram, por sua vez, novos elementos a esse complexo civilizatório, desencadeando experiências de mestiçagem que marcariam definitivamente a nossa fisionomia cultural.

Os processos de descolonização, no século passado, introduziram variáveis geopolíticas, através da territorialização esboçada pelos nascentes Estados nacionais. Cada país assumiu uma identidade peculiar no bojo da organização de modernas sociedades. Não obstante isso, floresceram áreas culturais homogêneas, compostas de vários países, em certo sentido configurando blocos geoculturais.

São exatamente essas formações que dão origem a conjuntos geoeconômicos do Caribe, dos Andes, da Amazônia, do Cone-Sul etc. - ensejando mercados regionais. Tais formações cimentam a colaboração entre distintos países que viabilizam intercâmbios comerciais, graças não só à contigüidade territorial, mas também à existência de traços culturais comuns. Isso os torna soli- dários, predispondo os respectivos cidadãos a relacionar-se positivamente com os seus vizinhos.

No entanto, a emergente cooperação latino-americana, depois de muito distanciamento e até mesmo de conflitos, enfrenta um desafio potencial: a desagregação cultural provocada pelo impacto das comunicações globais. As novas tecnologias da informação destroçam as fronteiras físicas entre as nações, expondo os indivíduos a uma cultura mundializada que pode minar pela base as identidades nacionais ou regionais.

Como lidar com esse fenômeno que o comunicólogo canadense Marshall McLuhan chamou de aldeia global? Quais as chances de sobrevivência das identidades latino-americanas diante de uma cultura planetária, como bem caracterizou o sociólogo francês Edgar Morin? Se o mercado global traz no seu bojo potencialidades multiculturais, de acordo com o diagnóstico do antropólogo brasileiro Renato Ortiz, qual o espaço que as culturas latino-americanas podem ocupar no novo mapa do mundo?

\section{O AUTOR}

\section{José Marques de Melo}

Titular da Cátedra Unesco de Comunicação para o Desenvolvimento Regional - Universidade Metodista de São Paulo. 
Para enfrentar tais enigmas torna-se indispensável delinear a natureza políticoeconômica da globalização.

\section{GLOBALIZAÇÃo E MULTICULTURALISMO}

É indiscutível que a divisão internacional do trabalho, neste final de século, vem se caracterizando pela vigência de uma economia globalizada, superando os limites territoriais antes circunscritos aos espaços nacionais. A globalização não é, contudo, "um fato acabado, mas um processo em marcha, que enfrenta obstáculos, sofre interrupções, mas generaliza-se e aprofundase como tendência. Por isso há nações e continentes nos quais a globalização pode desenvolver-se ainda mais, tem ainda espaços a conquistar"'2.

Esse fenômeno foi percebido pela mundialização das comunicações, gerando uma nova cultura, massiva e transnacional. Trata-se de uma cultura internacional-popular, cujo terreno de base é o mercado consumidor.

Nesse panorama dilui-se o conceito de nacionalidade. "Existe uma história da formação das nacionalidades, cristalizando maneiras de pensar, formas de conduta. Mas algumas objeções podem ser levantadas a esse entendimento do problema." (...) "Do ponto de vista histórico, é preciso reconhecer que a nação e, por conseguinte, as identidades nacionais são fatos recentes na História dos homens. Por que reificá-los, imaginando que representariam uma espécie de término da humanidade? (...) Se a autonomia do Estado-nação encontra-se comprometida com o processo de globalização da sociedade, por que a cultura permaneceria intacta, imune aos humores do sistema mundial?"3

Dentro de tal processo, emergem formações econômicas de novo tipo, determinadas pela geografia. Trata-se dos blocos regionais, aglutinando nações antes separadas por etnias, línguas ou religiões, que hoje se sentem compelidos a superar divergências históricas para inserir-se dinamicamente na economia global.

Trata-se da emergência de uma nova civilização que, tanto no caso europeu quanto no caso norte-americano, encontrou de início feroz resistência.

O termo civilização pode parecer pretensioso. Mas possui abrangência suficiente "para incluir assuntos tão variados quanto tecnologia, vida familiar, valores, moralidade sexual e epistemologia. Mudanças rápidas e raciais estão ocorrendo em cada uma das muitas dimensões da sociedade. Mude tantos elementos sociais, tecnológicos e culturais de uma só vez e você estará criando não apenas uma transição, mas uma transformação, não somente uma nova sociedade mas, pelo menos, os fundamentos de uma sociedade totalmente nova" 4 .

\section{VOCAÇÃO DO MERCOSUL}

Nesse contexto situa-se portanto a criação do Mercosul, reunindo os países localizados no pólo extremo das Américas. Ele decorre do compromisso histórico que Argentina, Brasil, Paraguai e Uruguai assumiram em 1991 para enfrentar coletivamente os processos de mudanças internacionais, 
regionais e globais. Superando divergências históricas, os quatro países buscaram caminhos mais inteligentes de integração e cooperação. Sua meta inicial é a formação de uma união aduaneira, configurando um mercado de aproximadamente 210 milhões de consumidores.

As propostas que determinaram a formação do Mercosul estão bem nítidas no texto do Tratado de Assunção:

a) Acelerar os processos de desenvolvimento econômico com justiça social, ampliando e integrando as atuações e dimensões dos mercados nacionais. Para tanto, torna-se indispensável aproveitar eficazmente os recursos disponíveis, preservando o meio ambiente, melhorando as interconexões físicas, coordenando as políticas macroeconômicas e complementando os diferentes setores da economia com base nos princípios da gradualidade, flexibilidade e equilíbrio.

b) Promover o desenvolvimento científico e tecnológico dos Estados-partes, modernizando suas economias para ampliar a oferta dos bens e serviços disponíveis, a fim de melhorar as condições de vida de seus habitantes.

Essa vontade política atende a dois objetivos estratégicos:

I) Obter uma adequada inserção internacional para os nossos países, em vista da evolução dos acontecimentos mundiais, caracterizados pela consolidação de grandes blocos econômicos regionais.

II) Não perder de perspectiva a integração da América Latina como meta de desenvolvimento progressivo no plano continental.
Fica evidente, pois, que a formação do Mercosul constitui uma resposta dos países do Cone-Sul às novas possibilidades de cooperação inter-regional, diante do cenário da globalização econômica.

Mas o Mercosul não pode ser entendido absolutamente como uma "fortaleza regional"s. Nossa origem cultural iberoamericana e nossa contigüidade geográfica norte-americana representam prioridades inadiáveis.

A Europa constitui o nosso maior parceiro econômico, daí o recente acordo União Européia - Mercosul.

No mesmo plano, encontra-se a nossa relação com o Nafta ${ }^{6}$ (North America Free Trade Agreement), cujo diálogo vem transcorrendo desde a Cúpula das Américas, realizada em Miami em 1994, e intensificado agora durante a visita do presidente Clinton ao Brasil e à Argentina. Nossa integração à $\mathrm{ALCA}^{7}$ (Área de Livre Comércio das Américas) pressupõe indiscutivelmente a consolidação prévia do Mercosul, numa estratégia de hegemonia compartilhada, como bem o definiu o presidente brasileiro Fernando Henrique Cardoso.

Se as articulações de natureza econômica caminham velozmente, complementando mercados antes separados, as iniciativas no campo da cultura e da comunicação mostram-se tímidas e pouco eficazes. Resultado disso tem sido a escassa participação da opinião pública na construção do mercado único sul-americano, o que corresponde a um desafio a ser enfrentado pelos especialistas em Comunicação.

5. CHACON, Vamireh. O Mercosul: a integração econômica da América Latina. São Paulo: Scipione, 1996. p.67.

6. Nafta (North America Free Trade Agreement), Tratado de Livre Comércio da América do Norte. Trata-se de uma área de livre comércio entre EUA, Canadá e México; com restrições e cotas para determinados produtos e trânsito de mão-de-obra.

7. ALCA (Área de Livre Comércio das Américas). Constitui-se numa proposta de zona de livre comércio entre os 34 países do Continente Americano, exceto Cuba, com previsão para vigorar a partir de 2005. 
Temos nos comportado como se os fatos dissessem respeito exclusivamente aos governos nacionais, não afetando os cidadãos. Por isso não surpreende que o tema Mercosul ainda não tenha conquistado projeção na agenda da imprensa diária dos nossos países, a não ser em situações de crise como a que precedeu a recente visita do presidente Clinton, quando a mídia explorou o perigo de implosão do Mercosul, em face da proposta dos EUA de adesão isolada dos países do bloco regional à ALCA.

Uma pesquisa feita pela UMESP Universidade Metodista de São Paulo em 1996, sintomaticamente numa semana em que o presidente Fernando Henrique Cardoso fazia uma visita à Argentina, constatou que o espaço atribuído pelos jornais brasileiros a esse fato era insignificante. A maior cobertura dada ao Mercosul, naquela semana, estava localizada no jornal Zero Hora, de Porto Alegre, ocupando 11.731 centímetros-coluna, o que representava apenas $1,3 \%$ de todo o espaço impresso do jornal. Nos jornais do Sudeste brasileiro, onde se encontram os principais formadores da opinião pública nacional, o noticiário sobre o Mercosul era três vezes menor que o espaço encontrado na imprensa gaúcha. Na imprensa do Norte era trinta vezes menor ${ }^{8}$.

\section{DESAFIOS COMUNICACIONAIS}

$\mathrm{Na}$ verdade, tal fenômeno reflete aquela situação de "incomunicação compulsiva"9, que marcou historicamente os povos latino-americanos e que constituíra motivo para a decepção precoce de Bolívar, cujo so- nho de unir politicamente o continente permanece inconcluso.

Nossos colonizadores - portugueses e espanhóis - são os "povos mais miscigenados da Europa, por suas origens (céltica, romana, germânica, visigótica e árabe)"'10. Por isso mesmo, eles tão bem se adaptaram aos trópicos. "A herança das línguas portuguesa e espanhola é o principal penhor de um denominador comum cultural. Não por um desejo de volta ao passado, e sim para a continuação da construção ecumenicamente mestiça de novas culturas e novas civilizações próprias, no quadro de um mercado comum econômico" 11 .

Nesse sentido é que o principal desafio comunicacional do Mercosul reside na superação das barreiras lingüísticas que ainda subsistem no conjunto das nossas populações. Torna-se urgente um vasto projeto de cooperação cultural, começando pela mútua necessidade do aprendizado do idioma espanhol no Brasil e do português na Argentina, Paraguai e Uruguai. "Isso deve dar numa base recíproca de aprofundamento, para a superação de antigos e novos preconceitos"12.

Torna-se inadiável, também, o debate sobre as questões midiáticas, bem como a formulação de uma política regional de comunicação sintonizada com as demandas das nossas sociedades civis. Temos hoje indústrias midiáticas modernas, que começam a fazer intercâmbios, mas falta-nos um consenso que garanta fluxos internos mais equilibrados.

Permanecem pouco exploradas questões cruciais. Por exemplo, convém ao Mercosul fixar reservas de mercado para os pro-

8. ANDRADE, Antônio et al. Mercosul é notícia? São Bernardo do Campo: UMESP, 1997. p.8.

9. PASQUINI, José Maria. Incomunicación compulsiva. In: BARROS, L. M. Comunicación, cultura y cambio social. São Paulo: WACC, 1994. p.39.

10. CHACON, Vamireh. O Mercosul... op.cit. p.72.

11. CHACON, V. O Mercosul... op.cit. p.72.

12. CHACON, V. O Mercosul... op. cit. p.70. 


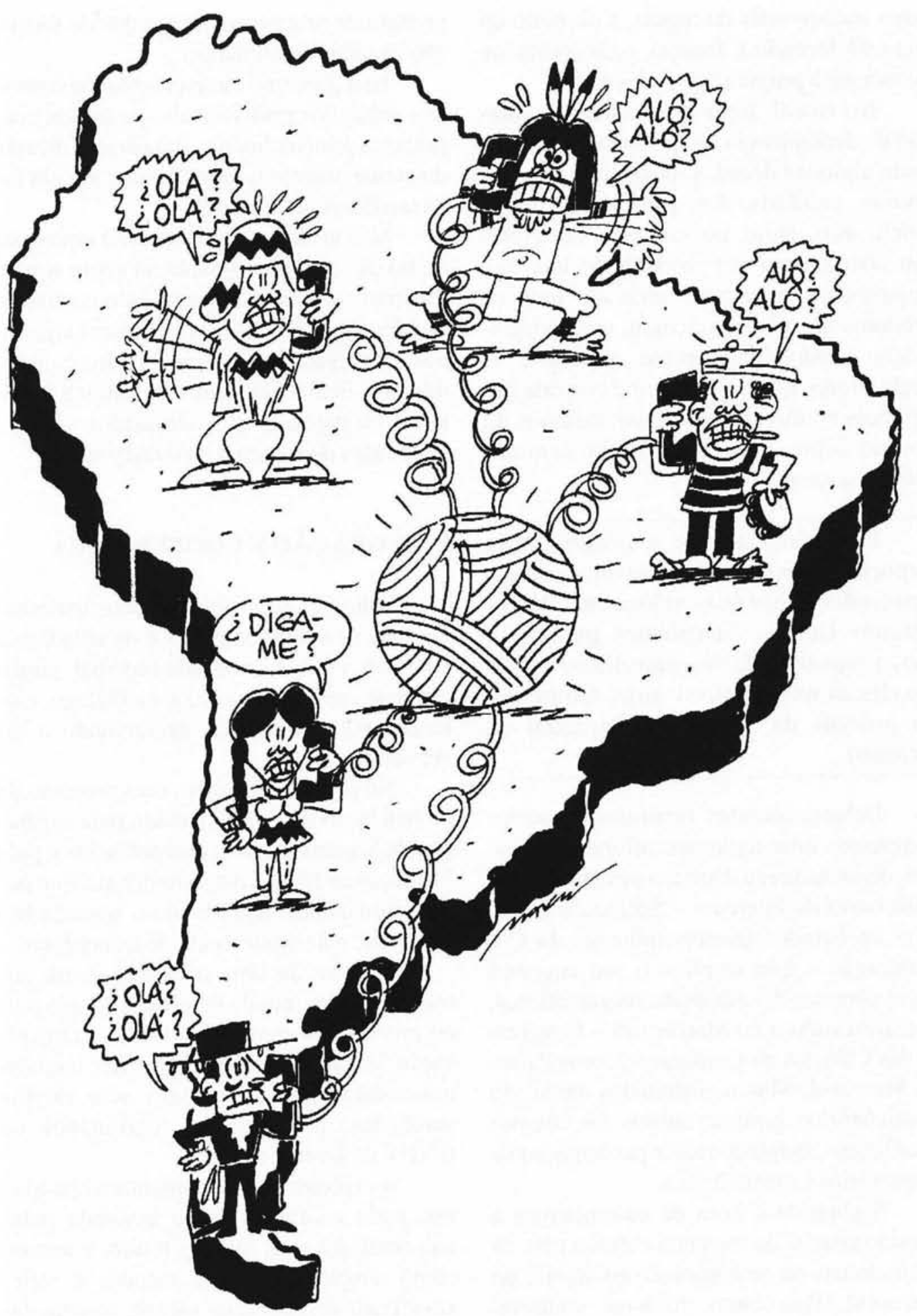


dutos audiovisuais da região, a exemplo do que está fazendo a Europa, principalmente no tocante à programação televisiva?

No Brasil, logramos superar a situação de dependência de que padecemos durante algumas décadas, possuindo uma televisão caudária dos programas norteamericanos. Hoje, nossas redes de televisão aberta, sem necessidade de leis que impusessem reserva de mercado para os produtos nacionais, veiculam uma programação predominantemente brasileira. A Rede Globo, que desfruta uma cômoda hegemonia no mercado nacional, difunde, no horário nobre, uma programação cem por cento nacional.

É lamentável que a programação importada, mesmo minoritária, continue a proceder quase que exclusivamente dos Estados Unidos. Veiculamos pouquíssimos programas latino-americanos, dentre eles as novelas mexicanas. Quase nada procede da Argentina, Paraguai ou Uruguai.

Debates recentes, ocorridos em vários congressos inter-regionais, afloraram questões dessa natureza. Destaco principalmente a iniciativa da Intercom - Sociedade Brasileira de Estudos Interdisciplinares da Comunicação - que ampliou o seu encontro anual para dar-lhe dimensão megarregional, transformando-o no Mercomsul - Congresso das Ciências da Comunicação nos Países do Mercosul. Mas os resultados ainda são insatisfatórios, porque restritos aos círculos acadêmicos, exigindo maior participação de empresários e profissionais.

É chegada a hora de enfrentarmos a questão crucial do mercado comum para os profissionais da comunicação no âmbito do Mercosul. Para tanto, torna-se inadiável pensarmos programas integrados de formação de recursos humanos.

Isso pressupõe intercâmbio universitário, colóquios profissionais, pesquisas conjuntas e, principalmente, uma ampla difusão do conhecimento midiático estocado em cada um dos nossos países.

Mas aí defrontamo-nos com uma triste realidade: a mútua ignorância sobre o pensamento comunicacional gestado no âmbito do Mercosul. São poucos os autores argentinos ou uruguaios conhecidos, lidos e discutidos no Brasil. São raros os autores brasileiros ou paraguaios disseminados nas universidades do Uruguai ou da Argentina.

\section{INTEGRAÇÃO E COOPERAÇÃO}

O limiar do século XXI antecipa cenários que desafiam os povos e os cidadãos a construírem uma sociedade mundial, politicamente embasada na paz e no diálogo, culturalmente polifacética, preservando a diversidade.

No plano econômico, esse processo de globalização tem sido marcado pela superação da hegemonia das superpotências e pela formação de blocos megarregionais, que podem tornar mais equilibrado o intercâmbio comercial e a transferência de tecnologias.

Trata-se de uma realidade vivida intensamente no mundo empresarial, cujo palco privilegiado tem sido a OMC - Organização Mundial do Comércio, mas também nas esferas governamentais, sem dúvida acionadas, pelos fóruns legitimados da ONU e da Unesco.

A evidência dessa conjuntura histórica não pode continuar sendo ignorada pelas universidades que, quando muito, a tomam como simples objeto de estudos e reflexões.Trata-se, agora, de sair da contempla- 
ção à realização, protagonizando feitos que permitam moldar inteligentemente a globalização acadêmica e profissional, instaurando processos eficazes de cooperação científica, pedagógica e corporativa.

As novas tecnologias colocam à disposição dos pesquisadores e dos profissionais, no mundo inteiro, recursos capazes de superar carências cognitivas e neutralizar barreiras à inovação.

Permanecer isolados dentro das fronteiras nacionais, atemorizados pelos velhos fantasmas dos imperialismos, é optar por estratégias suicidas.

A inserção dos povos e das culturas nesse universo complexo depende da capacidade nacional para engendrar alianças geoeconômicas ou político-culturais compatíveis com os interesses coletivos. Eles não se restringem às demandas localizadas, micro ou megarregionais, mas pressupõem a preservação da paz entre os povos como alternativa possível para garantir a saúde do planeta e o bem-estar dos cidadãos.

Resumo: 0 processo de globalização vem provocando a criação de blocos econômicos regionais. Contudo, essa estratégia defensiva dos países contiguamente geográficos, como é o caso do Mercosul, para conquistar espaços no novo mapa do mundo, não vem sendo acompanhada de uma política de preservação das identidades culturais. 0 multiculturalismo ensejado pela globalização midiática abre oportunidades para a projeção mundial daquelas culturas capazes de criar mecanismos internos de comunicação intercultural e ao mesmo tempo disseminar internacionalmente os valores da cultura megarregional.

Palavras-chave: internacionalização midiática, Comunicação intercultural, globalização, multiculturalismo, cultura megarregional

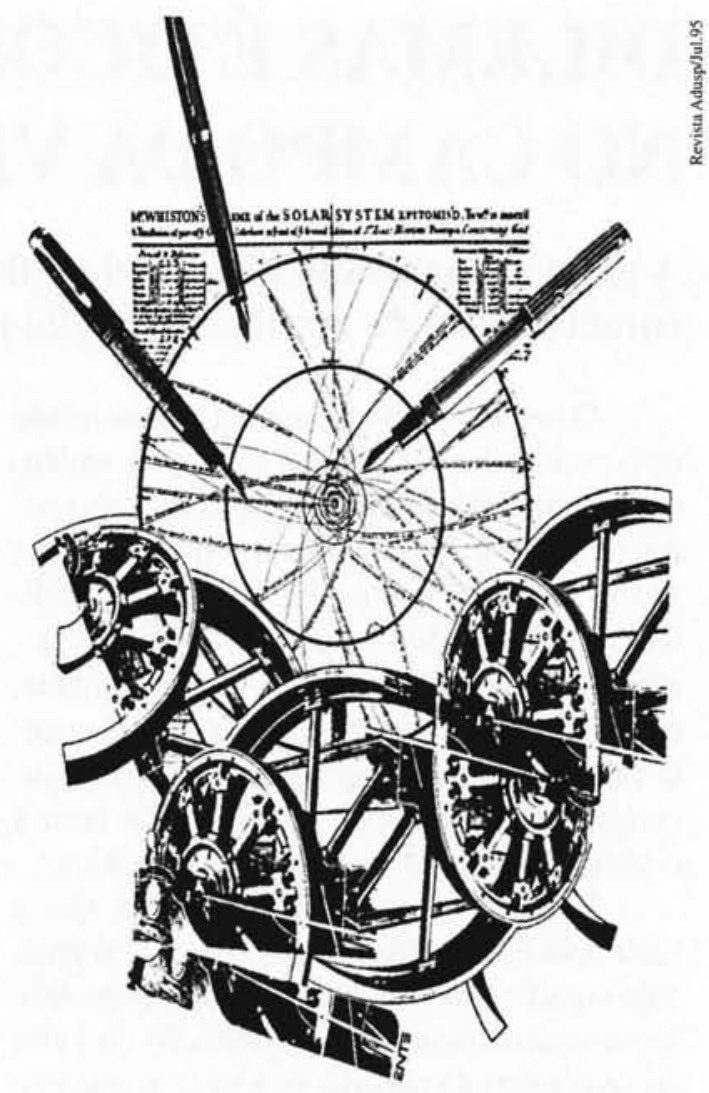

Abstract. The globalization process has been generating the establishment of regional economic blocks. However, this defensive strategy of countries that are contiguous geographically, such as the Mercosur Countries, in order to conquer spaces in the new world' map, has not been followed up by a policy for the preservation of the cultural identities. The multiculturalism desired by the media globalization opens opportunities for the world projection of the cultures that are capable of creating internal intercultural communication mechanisms, and, at the same time, of disseminating the megarregional cultural values internationally.

Key words: mediatic internationalization, intercultural communication, globalization, multiculturalism, megarregional culture 